\title{
Os conflitos na relação avaliação e qualidade da educação
}

\section{The conflicts in the evaluation and educational quality relationship}

\author{
Isabel Franchi Cappelletti ${ }^{1}$
}

\begin{abstract}
RESUMO
Este artigo pretende discutir a relação entre avaliação educacional e qualidade da educação. A discussão desta temática teve como horizonte a racionalidade emancipatória, considerando a educação como espaço da crítica histórico-política, analisando o contexto a partir da década de 1990 que dá sentido histórico aos temas aqui tratados. O texto traz uma reflexão sobre o significado da avaliação, da gestão escolar e da qualidade da educação, quando as opções metodológicas do processo avaliativo tendem para a exclusão ou para a emancipação de seus participantes. Finalmente, discute a precariedade da formação de professores no que diz respeito à avaliação da aprendizagem e apresenta algumas questões que deveriam ser consideradas na formação dos professores.
\end{abstract}

Palavras-chave: avaliação; qualidade da educação; políticas públicas.

\begin{abstract}
This article intends to discuss the relationship between educational assessment and educational quality. The discussion of this theme had as its horizon the emancipatory rationality, considering education as an object for historic-political criticism, analyzing the context from the nineties since it gives historical meaning to the themes that were analyzed here. The text presents a reflection about the meaning of assessment, of school management and of educational quality, when methodological options for the evaluation process tend to the exclusion or to the enfranchising of the participants. Finally, it discusses precariousness in the teachers' formation
\end{abstract}

DOI: $10.1590 / 0104-4060.41464$

1 Pontifícia Universidade Católica de São Paulo. Programa de Pós-Graduação em Educação: Currículo. São Paulo, São Paulo, Brasil. Rua Monte Alegre, no 984, Perdizes. CEP: 05014-901. E-mail: isafrancappell@bol.com.br 
whereas learning evaluation and it presents some questions that should be considered in teachers' formation.

Keywords: evaluation; educational quality; public policies.

\section{Introdução}

A problemática que abarca os temas avaliação e qualidade da educação é bastante complexa, envolvendo um emaranhado de conceitos de variadas vertentes epistemológicas, políticas e educacionais, que precisam ser reinterpretados no contexto histórico em que estão sendo discutidos.

A discussão dessa temática será feita no horizonte da racionalidade emancipatória, considerando a educação como espaço da crítica histórico-política, da construção coletiva do conhecimento, da libertação humana do homem como agente de transformações sociais.

Dessa forma, objetiva-se no presente artigo discutir sobre a relação indissociável entre avaliação e qualidade, no sentido de analisar as dificuldades de se atingir a qualidade sociocultural desejada para a educação.

Muitas questões estão envolvidas nesta discussão, mas aqui privilegiou-se aquelas que são recorrentes na literatura, nos resultados de pesquisa e na experiência dos que militam no campo da avaliação. Três aspectos na reversão do status quo em avaliação são fundamentais: a opção epistemológica/metodológica, a gestão escolar e a formação de professores.

A avaliação educacional se constitui no campo de estudo da autora que lhes fala e certamente por essa razão acabará sendo o eixo condutor das questões aqui tratadas. Necessário se faz retomar algumas situações e circunstâncias contextuais da década de 90 que dão sentido histórico aos temas aqui tratados.

Como consequência da democratização do ensino atingiu-se, no Brasil, na década de 90, a universalização do acesso de nossas crianças e adolescentes de 07 a 14 anos no Ensino Fundamental obrigatório. Segundo dados da Pesquisa Nacional por Amostra de Domicílio - PNAD, de 2003, o Brasil universalizou o Ensino Fundamental, chegando a ter $97,2 \%$ da faixa etária citada frequentando escolas. (CAMPOS, 2008).

A democratização em relação ao acesso foi um avanço, entretanto, não foi suficiente para a educação avançar também na direção da qualidade desejada. Ao contrário: o aumento da demanda, sem a necessária criação de condições estruturais, trouxe novos problemas para o processo educacional. 
Locais para atender aos alunos foram improvisados, os turnos de funcionamento das escalas triplicaram, sem falar da necessidade de contratação de professores, que nem sempre estão preparados para a função docente.

A expansão das redes escolares significou também a expansão do mercado de trabalho para professores, incorporando no magistério pessoas de origem social não muito diferente do alunado formado em instituições privadas de ensino superior, geralmente de baixa qualidade. (CAMPOS, 2008, p. 8).

Diante dessa realidade a questão da qualidade passa a ser pauta das discussões educacionais, estendendo-se para a sociedade em geral.

Com o objetivo de melhorar a qualidade de ensino, o governo cria um sistema de controle com as avaliações externas, que acabam por ocupar a centralidade das políticas da educação brasileira.

No governo de Fernando Henrique Cardoso (1994-2001) foi criado o Sistema Nacional de Avaliação, instituindo os exames externos como principal procedimento avaliativo, tendo o desempenho dos alunos nesses exames como o principal indicador da qualidade da educação.

A construção de indicadores de qualidade é um processo complexo que envolve muitas variáveis que não podem ser ignoradas. Mais do que uma contabilização de dados, diante dos resultados é preciso que a equipe de educadores da escola analise criticamente o que foi solicitado nas provas e os resultados obtidos por seus alunos, como o objetivo de produzir uma proposta pedagógica necessária à escola.

Se não houver uma discussão das comunidades educativas sobre os resultados da avaliação externa e dos índices alcançados, ela passa a ter apenas as funções classificatórias e seletiva, caracterizando-se como controle administrativo do Estado. "[...] o mote do MEC na era FHC, raramente mencionado agora, é a ênfase dada para a supervisão e controle administrativos, com vistas à autorização, credenciamento das instituições e cursos". (SANTOS, 2002 apud CAPPELLETTI, 2005, p. 106).

Nesse movimento a administração, a estrutura e a organização da escola também são colocadas em foco, quando a gestão passa a significar supervisão e controle administrativos, exercendo a função de implantar as mudanças institucionais reclamadas pelas políticas públicas.

Há uma estreita articulação entre a reforma da Educação Brasileira, a reforma da Educação Básica e a reforma da gestão escolar implementadas na década de 90. 
Zanardine (2008) afirma que:

[...] mais do que isso, é possível situar a Reforma da Educação e da gestão escolar como componentes da reforma do Estado e da necessária implementação da eficiência gerencial e mercadológica para o atual estágio de configuração do modo capitalista de produção da existência. (ZANARDINE, 2008, p. 152).

Assim, na década de 90, busca-se a qualidade da educação do duplo controle:

- avaliação de resultados por meio de exames;

- gestão escolar como agente administrativo das ações do governo.

Não é essa a qualidade educacional que colocamos no horizonte de nossas reflexões, nem mesmo a gestão escolar que gostaríamos de ter.

\section{As questões em pauta}

A questão da avaliação educacional, em função das políticas públicas que a regulamentam, como a Lei de Diretrizes e Bases da Educação Nacional - LDB (Lei nº 394/96), o Plano Nacional de Educação (PNE - 98), medidas provisórias e vários decretos, trouxe o reconhecimento legal da importância da avaliação, quando declara que seu objetivo é a melhoria da qualidade de ensino. Entretanto, as políticas públicas, ao fazerem uso dos resultados, enfatizam os escores quantitativos, usando procedimentos classificatórios em função desses resultados, introduzindo nas instituições de ensino o modelo de avaliação como medida.

A absorção do processo de avaliação pela instituição leva à absorção dos próprios conceitos que deram origem ao sistema de avaliação. Tais conceitos nem sempre são universais, nem sempre há acordo sobre quais seriam os mais adequados para uma instituição ou para outra. Os órgãos centrais tendem a montar essas sistemáticas em função de seus próprios compromissos, dos seus próprios conceitos, das opções particulares que fazem e terminam difundindo tais conceitos no âmbito das organizações que fazem uso dos seus sistemas de avaliação. (FREITAS, 2001, não paginado). 
Ao assumir a proposta de avaliação do governo a instituição acaba por assumir também os pressupostos teóricos de tais propostas que se alinham na contramão de uma perspectiva mais globalizante, mais crítica, e com forte apelo social a serviço da formação.

O modelo estatal reduz a avaliação educacional a um procedimento de controle definindo, hierarquicamente, normas para todo o sistema de ensino.

Sobrinho (2002) tem contribuído para aprofundar as discussões sobre o significado dos exames nacionais em relação à melhoria da qualidade da educação. Enfatiza que ao considerarem a objetividade, a experimentação e as provas estatísticas como suficientes para avaliar a educação, deixam de lado uma parte essencial da realidade que envolve valores, idiossincrasias, necessidades, habilidades, que não pode ser expressa em expressões matemáticas e estatísticas.

Cabe retomar a questão da gestão escolar, que no fluxo do sistema de avaliação externa acaba exercendo pressão sobre os professores para que os alunos tenham boas notas nos exames, adequando a cultura e o currículo da escola aos projetos políticos do Estado.

Em pesquisa realizada e publicada sob o título "Análise Crítica das Políticas Públicas da Avaliação" (CAPPELLETTI, 2005), pudemos perceber o acordo passivo de professores em relação à proposta de avaliação e ao uso que tem sido feito dos seus resultados. As críticas mais frequentes diziam respeito às questões da prova e poucos tomaram conhecimento dos resultados de sua escola.

Em pesquisas mais recentes, Rodrigo Rodrigues (2011), Jociane Santos Peixoto (2011) e Orandes Rocha (2012), tendo como recorte a avaliação e a atribuição de bônus, realizada pela Secretaria de Educação do Estado de São Paulo, encontram críticas mais severas e criticam a mudança significativa na seleção de conteúdos, de acordo com o currículo oficial, com o objetivo de preparar os alunos para a prova em função do cumprimento de uma meta. Enfatizam o constrangimento do ranking e as cobranças pela superação dos resultados. As professoras se sentem muito pressionadas, o que faz com que decidam por um currículo oficial, deixando de lado o currículo necessário para $\mathrm{o}$ atendimento dos alunos.

Dessa forma, não entendemos que com a grande pressão gerada pelo SARESP, exista a possibilidade de criar novos canais de diálogos. Como vimos os professores precisam seguir o currículo oficial, sob pena de terem o nome de suas escolas estampadas nos jornais como a pior escola. (PEIXOTO, 2011, p. 83). 
Ainda no estado de São Paulo, existe um complicador que é a atribuição de "bônus" aos profissionais da escola bem sucedida em relação às metas estabelecidas pela Secretaria da Educação. Além de rejeitarem o "bônus", solicitam melhoria das condições de trabalho e a proposição de um plano de carreira docente/decente, sentem-se ainda mais pressionados a "formatar" o currículo de acordo com as exigências do controle estatal. E o círculo perverso se fecha: seguir rigidamente o currículo oficial, cobrando dos alunos um bom desempenho nos exames, para que a escola possa receber o "bônus". (ROCHA, 2012).

Entretanto, mesmo com a mudança sentida em relação às críticas, que recentemente foram mais severas, mesmo assim, não chegam a discutir questões mais complexas como a questão da educação vista como "quase-mercado" e nem mesmo o "Estado-Avaliador" como importante articulador para a implementação de políticas de privatização e mercadorização da educação. E nessa articulação, o currículo nacional e os exames são condições prévias para que essas políticas ocorram.

Produz-se assim um mecanismo de "quase-mercado", em que o Estado, não abrindo mão da imposição de determinados conteúdos e objetivos educacionais [...] permite ao mesmo tempo que os resultados/produtos sejam também controlados pelo mercado. (AFONSO, 2005, p. 22).

As políticas públicas de avaliação têm estimulado a competição interinstitucional, quando assumem a lógica da ideologia de mercado, cuja ênfase é posta nos produtos da educação. E, para ter sucesso na competição mercadológica, usam diferentes estratégias para que o resultado dos exames seja alvissareiro para a instituição, como solução para evitar o desconforto. Pela pesquisa que realizei em 2005, já referida, foi possível conhecer algumas delas:

- impedir que alunos com baixo rendimento escolar fizessem exames;

- maior rigor na aprovação de alunos na série que antecede a realização dos exames;

- cursinhos preparatórios para os exames;

- treinamento em provas.

Há outras táticas utilizadas para que o aluno se acumplicie na tarefa de melhorar a nota da instituição a qualquer custo: descontos em mensalidades para bons desempenhos, sorteio de prêmios ou brindes, e até como se viu na imprensa, escola presenteando com um carro seu aluno de melhor desempenho. (SANTOS, 2002, p. 111). 
A avaliação assim concebida traz para o interior das instituições não só os pressupostos que a ordenam, mas também a concepção de qualidade reduzida à questão da obtenção de bons resultados nos exames nacionais. $\mathrm{O}$ currículo acaba sendo definido pelo uso que se faz dos resultados dos exames, abrindo espaço para o controle do mercado.

A concorrência se instala e as instituições de ensino apressam-se em divulgar seus resultados como o principal, em muitos casos o único, indicador da pretensa "qualidade educacional": faixas, propaganda, slogans, e as escolas nota dez ganham visibilidade na mídia.

Políticas educacionais como os Parâmetros Curriculares Nacionais - PCNs e o Sistema Nacional de Avaliação - SNA justificam o estabelecimento de tais propostas no sistema nacional de ensino tendo como objetivo a obtenção da qualidade de ensino. Entretanto, não esclarecem o significado que atribuem à questão da qualidade, e nem mesmo propõem indicadores conceituais que possibilitam sua avaliação.

Mesmo implícita nos Parâmetros Curriculares Nacionais e na proposta do Sistema Nacional de Avaliação, a ênfase que é dada em "indicadores, padrões, produtos e resultados" reduz as concepções de avaliação e de qualidade para a expressão "controle de produtos".

A lógica neoliberal reduz o tamanho e as funções do Estado em relação à Educação, que tem como exemplo recente a municipalização quando a União delegou suas responsabilidades para os Estados e os Municípios.

A reforma de cunho mecanicista-mercadológica pôs em primeiro plano o controle de gastos públicos e a sua municipalização deixando a cargo da sociedade a captação de outras fontes financeiras, o que levou à deteriorização das escolas públicas e, por outro lado, corroborou para favorecer o novo mercado, ou seja, a rede privada de ensino [...]. (NOGUEIRA; WILHELM, 2011² apud DEITOS; LARA, 2012, p. 57).

As questões até aqui discutidas sobre a relação indissociável entre avaliação e qualidade mostram as dificuldades de se atingir a qualidade sociocultural desejada para a educação. Entretanto, toda crítica colocada até aqui traz também, implicitamente, o desejado e que precisa ser desvelado.

2 NOGUEIRA, F. M. G.; WILHELM, V. B. Análise Histórica e conceitual da Política de Educação Especial no Brasil e na Venezuela: explicando alguns contrastes e semelhanças. In: $5^{\circ}$ Seminário Nacional Estado e Políticas Sociais no Brasil, 2011, Cascavel. Anais do $5^{\circ}$ Seminário Nacional Estado e Políticas Sociais no Brasil. Cascavel: Edunioeste, 2011. v. 1. p. 1-13. 
Muitas questões estão envolvidas nesta discussão, mas privilegiou-se aquelas que são recorrentes na literatura, nos resultados de pesquisa e na experiência dos que militam no campo da avaliação. Três aspectos na reversão do status quo em avaliação são fundamentais: a opção epistemológico-metodológica, a gestão escolar e a formação de professores.

Não se pode mais aceitar que a avaliação se fundamente no positivismo como a única possibilidade de se atingir a verdade. "Não se trata atualmente de 'rejeitar a medição', mas de evitar a importação de uma ideologia positivista [...] apresentada como inevitável e a única garantia de cientificidade". (BONNIOL; VIAL, 2001, p. 95).

A atitude positivista diante da ciência traz para a avaliação pressupostos como a exigência da objetividade diante dos fatos (juízos de fato) da neutralidade e do afastamento do avaliador em relação ao objeto a ser avaliado, para que a construção de resultados corresponda à realidade objetiva, como verdade absoluta e universal, onde não há espaços para contestações. Essa relação sujeito/ objeto na construção do conhecimento avaliativo supõe que a realidade social é idêntica à realidade física/natural, é estável, constituída por fenômenos que se repetem e que são independentes da vontade dos sujeitos, de suas opiniões, valores e representações.

Em suma, os pensadores inscritos no universo da "Razão Positivista" em qualquer uma de suas visões "[...] têm como ideia fixa a busca da correspondência estrita e perfeita entre as representações humanas e a realidade representada". (ROMÃO, 1999, p. 30).

A adoção no processo avaliativo de pressupostos que levam à manipulação, domínio e controle das pessoas envolvidas, acaba manipulando o próprio avaliador, transformando-o em "coisa", em objeto.

A partir de pesquisas ${ }^{3}$ já realizadas em nosso contexto educacional sobre a avaliação da aprendizagem, pode-se afirmar que em geral os professores da Educação Básica trabalham a avaliação com os pressupostos da "ciência positiva", fazendo da docimologia a única alternativa para avaliar seus alunos.

Mudar de paradigma, para a maioria de nossos professores, significa navegar em águas desconhecidas, abandonando o apoio seguro da tecnologia que não abre brechas para as contestações.

3 Para maiores informações ver: 1) Avaliação na Educação Básica (1990-1998), sob a coordenação de Barreto e Pinto, Fundação Carlos Chagas; 2) Avaliação da Aprendizagem: um estudo sobre a produção acadêmica dos Programas de Pós-Graduação em Educação: PUCSP, USP, UNICAMP (2000-2007). Tese de Doutorado em Educação: Currículo, PUCSP, 2010, de Arnilde Marta Uler. 
O processo de avaliação, baseado exclusivamente em exames pontuais, mensuração, classificação, exclusão, é incompatível com o desenvolvimento educacional que tem no horizonte a qualidade sociocultural da educação.

A qualidade da educação deve ser buscada em um processo avaliativo que esteja a serviço da formação, favorecendo a apropriação do conhecimento eminentemente emancipador em uma expectativa dialético-crítica.

Nessa perspectiva a primeira questão que o avaliador tem que ter em mente é que o conjunto de informações que recolhe em um processo avaliativo não é um quadro pronto, mas fruto das relações sociais que se estabelecem durante o processo e das relações que os participantes estabelecem com a situação que está sendo avaliada.

Os pressupostos da atitude dialético-crítica abrem espaço para a subjetividade no discurso científico, para as relatividades de observação, quando coloca a avaliação em uma perspectiva histórico-social.

Na teoria crítica a ideologia não se opõe à ciência, derrubando o mito da neutralidade e do distanciamento do avaliador diante das situações que estão sendo avaliadas.

A visão dialética não confere independência ou prioridade nem para a realidade objetiva, nem para a subjetividade, mas submete-as ao critério da prática social, reconhecendo sua concretude e historicidade. (RODRIGUES, 1994). O sujeito do conhecimento e da realidade conhecida está dialeticamente relacionado: o sujeito interfere no real, mas sofre também as determinações concretas dessa mesma realidade. O processo de conhecimento integra-se na prática. (RODRIGUES, 1994).

Esses pressupostos implicam necessariamente para o avaliador na análise dos interesses, representações sociais, relações de domínio presentes no processo avaliativo tendo em vista a tomada de consciência e a superação dessas implicações. E isto só é possível na participação.

A atitude dialético-crítica da avaliação tem como essência o diálogo, a práxis como processo, a participação como compulsória e como finalidade a transformação social de relevância teórica e social.

Essa atitude diante da avaliação requer uma ruptura epistemológica em relação ao que ocorre nos sistemas de ensino, público e privado, do ensino fundamental ao universitário, uma tomada de consciência para a proposição de linhas de ação que considerem uma intervenção social solidária e que se ocupem da integração teoria/prática. (CAPPELLETTI, 2012, p. 12). 


\section{Uma segunda questão que merece ser discutida diz respeito à gestão escolar}

Se a avaliação educacional for concebida pelo gestor como acaba de ser discutida, numa perspectiva globalizante com forte apelo social, por certo terá à sua disposição informações valiosas sobre o desenvolvimento do trabalho escolar. Terá pistas, alternativas de ação para promover o desenvolvimento curricular em sua escola, assumindo sua função principal de gerir e criar cultura.

Numa perspectiva da educação crítico-dialética, em que se espera que os alunos aprendam a viver juntos, a respeitar a diversidade, assumindo responsabilidades sociais, é imprescindível que o ambiente da escola paute, em sua organização e gestão, essas relações.

Nesse sentido o processo de avaliação (de alunos, de professores, funcionários e da própria gestão) deverá ser construído coletivamente como um processo de formação em serviço. Evitar a qualquer custo punições, seleções, ranking de professores e funcionários.

Caberá ao gestor investigar criticamente as situações, gerir confrontos entre diferentes representações e relação teoria/prática, elucidando os fatores e as condições das representações, problematizando as situações em pauta, resignificando-as para transformá-las.

Ainda pela avaliação o gestor pode coletar informações para verificar ganhos e dificuldades no desenvolvimento de práticas gerenciais na escola, em relação às determinações das políticas públicas da educação, evitando ser apenas um cumpridor das demandas hierárquicas.

Pode e deve criar um espaço de reflexão no horizonte da política, como requisito legítimo da prática pedagógica envolvendo os profissionais da escola, alunos e pais.

Diante das políticas públicas há sempre uma infinidade de questões que podem ser colocadas pelo gestor: o que pensar sobre elas? O que dizem e o que escondem? Que valores estão explícitos/implícitos nas propostas governamentais? Qual o significado de qualidade da educação?

A qualidade da educação traduzida pelo sistema educacional oficial, pela universalização/democratização do ensino, precisa ser acrescida de outros valores e isso exige mudanças na gestão e na organização da escola.

Mudanças causam rupturas estruturais e, portanto, não devem prever objetivos imediatistas e resultados somente quantitativos. Exigem planejamento a longo prazo, participação da comunidade escolar na definição de objetivos, conceitos e sistemática de ação para que possam atuar como autores/sujeitos da 
ação, com sua experiência reconhecida, assumindo o papel que lhes cabe, em uma construção coletiva, concordando/discordando, expressando seus pontos de vista, sugerindo. Liberdade, autonomia, autodeterminação não são acessórios descartáveis. Ao contrário, estão no cerne do sentido da vida, a menos que imaginemos sem sentido. Seu sentido, na linha da qualidade, é participar.

Só com a participação dos envolvidos as mudanças serão compatíveis com a identidade da escola, favorecendo a apropriação de saberes e a compreensão da realidade que se quer transformar.

Novamente se faz presente a questão da avaliação agora tendo como objeto o projeto de mudança da escola.

O grau de dificuldade das múltiplas funções de um gestor aumenta quando existem crescentes exigências das decisões políticas. É importante que os gestores sejam considerados profissionais pedagógicos e não apenas executivos. Esta atitude concede-lhes um importante grau de credibilidade e de respeito, fornecendo-lhes um quadro de referência para a mudança. (GLATTER, 1994, p. 153).

Múltiplos conhecimentos, competências e habilidades para o exercício da gestão têm sido fartamente explicitados na literatura: competências de cunho administrativo, pedagógico, social, político e cultural. O mais importante, porém, é o gestor ter clareza do espaço ideológico que "habita", do contexto socioeconômico e político como cenário inevitável de suas ações, sem o que não terá como conquistar a tão desejada qualidade educacional em seu âmbito de trabalho.

Nossos professores, nossos gestores estão preparados para as ações que a opção por uma pedagogia crítica exige? Esta é uma questão que não pode ser ignorada quando se discute a avaliação como fundamental na busca da qualidade sociocultural da educação.

A participação em projetos estaduais e federais no campo da avaliação permite a afirmação de que quase a totalidade da rede nacional de ensino ainda adota um sistema de avaliação da aprendizagem pontual (bimestral, semestral, anual) com dias concentrados de provas, cujos resultados traduzidos em notas de zero a dez exercem a função classificatória e seletiva: aprovação, reprovação, exclusão.

Por que é tão difícil mudar? Além das questões já discutidas da interferência das políticas públicas nas práticas escolares, existem outras tantas questões, inclusive aspectos que apontam para as responsabilidades do professor/formador universitário.

A formação que é dada aos professores na formação inicial e continuada sobre a avaliação educacional é praticamente inexistente. 
Em pesquisa realizada por Elda Damásio de Souza (2007), foi possível constatar a inexistência de uma formação adequada em avaliação educacional nos cursos de Pedagogia. Em geral a avaliação educacional se constituía em um tema entre muitos, ou um módulo com horas insuficientes. Até mesmo os professores que tinham na ementa de sua disciplina uma bibliografia mais atualizada acabaram negando o seu discurso ao avaliar seus alunos apenas com provas pontuais, atribuindo-lhes notas para fins de aprovação/reprovação.

Hadji (2001) coloca em pauta uma questão importante que também traz dificuldades para a mudança necessária: "A interpretação das informações coletadas exige 'em princípio' referir-se a um quadro teórico que dê conta dos múltiplos aspectos (cognitivo, afetivo, social) das aprendizagens". (ALLAL, 1979, p. 156). Esta teoria está longe de ser construída.

A falta de formação e experiência no campo da avaliação impede a oferta aos estudantes, futuros professores, de vivências em processos avaliativos adequados e de acesso a modelos operacionais que possam ser ilustrativos de uma postura crítica em avaliação.

Em um curso de Licenciatura, com 52 alunos em sala de aula, nenhum deles havia passado por uma experiência avaliativa que não fosse por meio de provas e notas. Interrogados sobre o significado que a avaliação teve para eles, apontaram questões técnicas, sentimentos e mecanismos de resistência.

Começaram timidamente com aspectos mais técnicos como prova, nota, aprovação, reprovação... Estimulados passaram a externar sentimentos como medo, injustiça, pavor e prosseguiram falando em autoritarismo, cola, copiar do vizinho, descobrir o livro que o professor usa para selecionar questões da prova, protesto, etc. (CAPPELLETTI, 2005, p. 21).

A falta de referências teóricas e de vivências em modelos operacionais que favorecem a formação dificulta a mudança na direção de compreender e programar um processo de avaliação a serviço da formação e isso não depende apenas dos professores, mas principalmente dos formadores e dos pesquisadores para que esse obstáculo possa ser superado.

Necessário se faz rever a formação de educadores, inicial e continuada, no sentido de abrir espaço para uma temática tão complexa, como é a avaliação educacional, fundamental para a revisão e reconstrução do currículo.

A formação desejada em avaliação não pode ignorar, em relação aos seus participantes, a reflexão sobre o lugar ontológico que cada um habita, o "credo ideológico" que vem sendo construído. Essa clareza viabiliza a discussão sobre 
os fundamentos epistemológicos, modelos, paradigmas. Só então será possível optar por pressupostos que orientem os métodos e a operacionalização de práticas avaliativas.

Dependendo das opções a formação pode estar favorecendo um processo de controle, em que a relação de poder opressora traz como consequência o fracasso e a exclusão. Não é isso que se pretende.

A partir de uma longa experiência avaliando alunos, projetos e programas algumas questões surgem para serem aqui discutidas.

A proposta de formação de professores deveria levar em conta não só as questões relativas aos seus fundamentos, mas também as competências necessárias à ação avaliativa, na integração teoria/prática, a serviço da formação.

Nessa perspectiva formadora, a avaliação não ocorre pontualmente em algumas situações planejadas especificamente para avaliar resultados; o processo ganha destaque quando o conjunto de trabalhos realizados no cotidiano é valorizado, problematizado e ressignificado.

Problematizar as ações realizadas exige uma leitura reflexiva sobre o que é produzido, numa relação dialógica professor/aluno, favorecendo, no exame, a análise do que não foi percebido pelo processo de metacognição. Isso exige a busca contínua da compreensão do que está ocorrendo no processo do ensinar e do aprender.

A avaliação em processo exige que os professores saibam planejar procedimentos avaliativos como parte do cotidiano das situações de aprendizagem para que possam ser revistas e recriadas.

Talvez uma palavra-chave para caracterizar o processo avaliativo seja flexibilidade, que exige do professor, além de criatividade, a busca de pressupostos teóricos e critérios de análise para cada situação individual ou coletiva.

Ao analisar as produções dos alunos há de se respeitar as escolhas feitas em relação ao caminho que se faz para aprender, o erro como uma situação construtiva, as diferenças e o imprevisível.

A avaliação exige um contrato didático com a elaboração de estratégias e procedimentos de avaliação diferenciados, para que no movimento do percurso haja espaços para o replanejamento e para intervenções necessárias a partir das dificuldades surgidas em processo. Essas perspectivas só serão possíveis se o clima de trabalho for tranquilo pela transparência das intenções e ações em que os alunos reconhecem no ensinar a intenção de ajuda do professor em seu processo de aprender.

A intenção dessas considerações sobre a formação do professor tem por objetivo contribuir para sua formação e evitar que a avaliação continue sendo o principal instrumento escolar de exclusão. 
Em um processo de formação de professores o que se quer é que a avaliação seja concebida como um processo de emancipação, uma conquista política efetivada pela práxis humana, superando a dicotomia teoria/prática na busca do sucesso e da promoção dos participantes.

Ao discutir a possibilidade do sim e do não em relação à importância da avaliação na busca da qualidade da educação, muitas questões ainda poderiam ser aqui discutidas, mas, na impossibilidade de abordar todas elas, privilegiei a discussão sobre os fundamentos da avaliação, a gestão escolar e a formação de professores.

Fica o convite para que os leitores possam prosseguir nas reflexões que aqui apenas se iniciam.

\section{REFERÊNCIAS}

AFONSO, A. J. Avaliação educacional: regulação e emancipação. São Paulo: Cortez, 2005.

ALLAL, L. Stratégies d'évaluation formative: conceptions psychopédagogiques et modalités d'application. Berne: Peter Lang, 1979.

BONNIOL, J.-J.; VIAL, M. Modelos de avaliação: textos fundamentais. Porto Alegre: Artmed, 2001.

CAMPOS, M. M. A qualidade da educação: sob o olhar dos professores. São Paulo: FSM; OEI, 2008.

CAPPELLETTI, I. F. Avaliação educacional: fundamentos e práticas. São Paulo: Articulação Universidade/Escola, 2005.

CAPPELLETTI, I. F. Análise crítica das políticas educacionais. São Paulo: Articulação Universidade/Escola, 2005.

CAPPELLETTI, I. F. Opções metodológicas em avaliação: saliências e relevâncias nos processos decisórios. ROTEIRO, São Paulo: UNOESC, v. 37, n. 2, jul./dez. 2012.

DEITOS, R. A.; LARA, A. M. B. Estado e política educacional: o receituário do liberalismo social-democrata. EccoS, São Paulo, n. 29, p. 35-62, set./dez. 2012.

FREITAS, L. C. Implicações conceituais para uma prática avaliativa. Campinas: UNICAMP, 2001. Palestra proferida.

GLATTER, R. A gestão como meio de inovação e mudanças nas escolas. In: NÓVOA, A. As organizações escolares em análise. Portugal: Dom Quixote, 1994. 
HADJI, C. Avaliação desmistificada. Porto Alegre: Artmed, 2001.

LARA, A. M. de B.; DEITOS, R. A. (Orgs.). Políticas educacionais: um exame de proposições e reformas educacionais. Cascavel: Edunioeste, 2001.

PEIXOTO, J. S. Políticas públicas de avaliação do Estado de São Paulo e as repercussões na prática pedagógica: SARESP em foco. 112 f. Dissertação (Mestrado em Educação: Currículo) - Pontifícia Universidade Católica de São Paulo, São Paulo, 2011.

ROCHA, O. C. Jr. Avaliação docente no ensino público estadual de São Paulo: a bonificação por resultado na opinião do professor. 91 f. Dissertação (Mestrado em Educação: Currículo) - Pontifícia Universidade Católica de São Paulo, São Paulo, 2012.

RODRIGUES, P. As três lógicas da avaliação em dispositivos educativos. In: ESTRELA, A.; RODRIGUES, P. (Orgs.). Para uma fundamentação em avaliação. Lisboa: Colibri, 1994.

RODRIGUES, R. F. Usos e repercussões de resultados do SARESP na opinião de professores da rede estadual paulista. 112 f. Dissertação (Mestrado em Educação: Currículo) - Pontifícia Universidade Católica de São Paulo, São Paulo, 2011.

ROMÃO, J. E. Avaliação dialógica: desafios e perspectivas. São Paulo: Cortez: Instituto Paulo Freire, 1999.

SANTOS, W. Desvelando a retórica do Provão. In: CAPPELLETTI, I. F. Avaliação de políticas e práticas educacionais. São Paulo: Articulação Universidade/Escola, 2002.

SANTOS, W. A nova avaliação do ensino superior. In: CAPPELLETTI, I. F. Análise crítica das políticas públicas de avaliação. São Paulo: Articulação Universidade/Escola, 2005.

SOBRINHO, J. D. Universidade e avaliação: entre a ética e o mercado. Florianópolis: Insular, 2002.

SOUZA, E. D. A formação dos formadores em avaliação da aprendizagem: o processo de formação inicial em debate. 158 f. Dissertação (Mestrado em Educação: Currículo) - Pontifícia Universidade Católica, São Paulo, 2007.

ZANARDINI, I. M. S. Reforma do Estado e da Gestão Escolar: uma leitura da articulação via eficiência gerencial. In: FIGUEIREDO, Z.; DEITOS, R. A. (Orgs.). Educação, políticas sociais e estado no Brasil. Cascavel: Edunioeste, 2008.

Texto recebido em 21 de maio de 2015. Texto aprovado em 09 de julho de 2015. 
